\title{
Succesful Regional Anaesthesia and Surgical Gastrostomy for Head and Neck Cancer patients with Airway Obstruction
}

D. Vuckova; T. Gramosli; M. Gjorgon; D. Popevski; E. Stoicovski; Z. Mitrev Zan Mitrev Clinic, Skopje, Republic of North Macedonia

Background and Aims: Malnutrition and cachexia are frequent in Head and Neck Cancers (HNC) patients. These complications occur as a result of the cancer but worsened by surgery, radiotherapy or chemotherapy that further challenge oral intake but also airway obstruction.

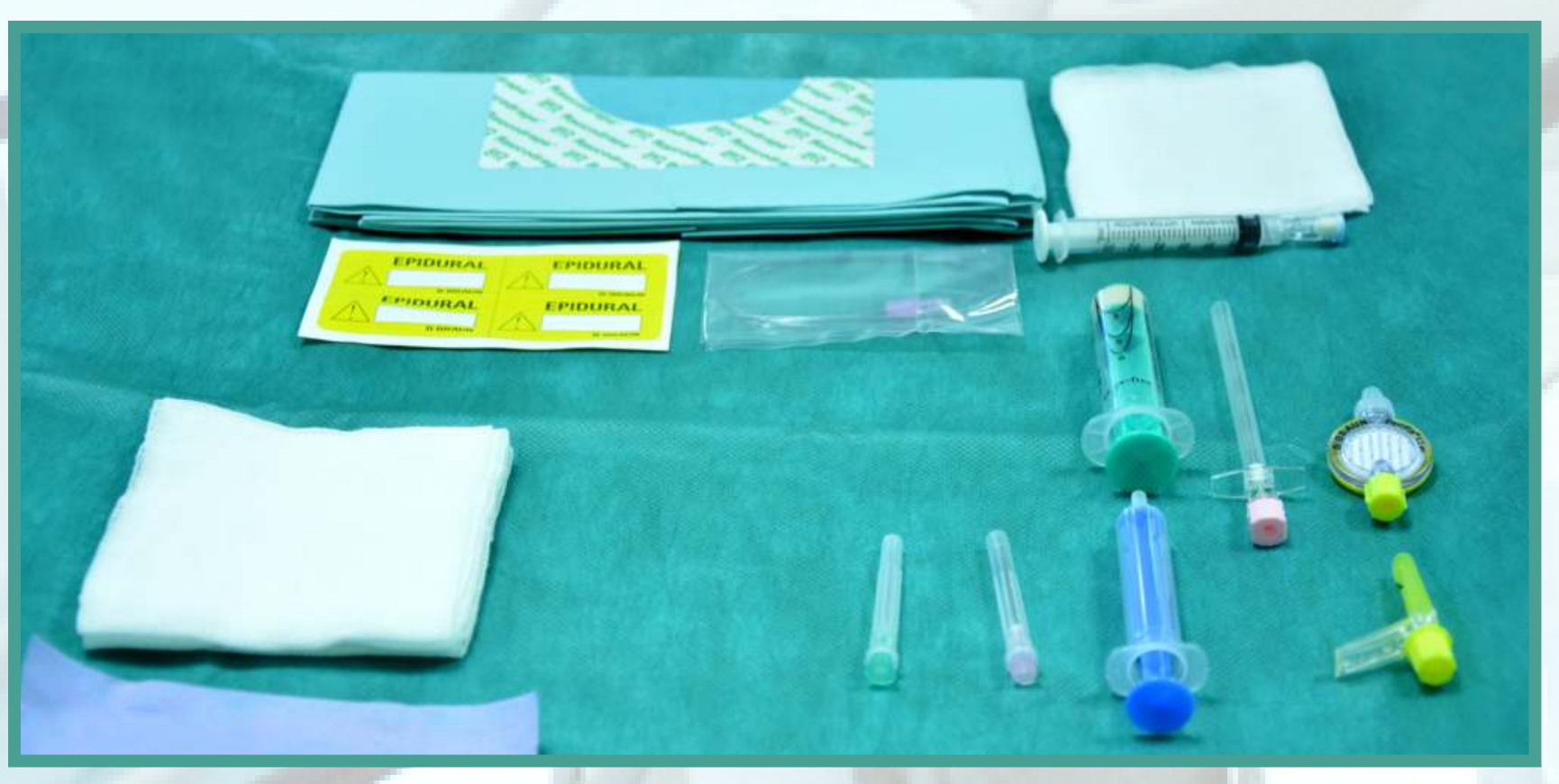

Case report: We present case of 82-year-old male with nasopharyngeal carcinoma, severe malnutrition following multimodality therapy and difficult airway. He was unable to consume solid foods and liquids, developing severe cachexia due to esophageal stricture, confirmed during an unsuccessful gastroscopy.

Refused by several hospitals, we opted for surgical gastrostomy under regional anesthesia, using epidural catheter placed T10/T11 and continuous 5\% bupivacaine. The procedure was uneventful and pain free. The epidural catheter was removed on the $2^{\text {nd }}$ postoperative day; patient discharged on the $4^{\text {th }}$ postop day, with functional gastrostomy. First follow up showed increase in body weight.
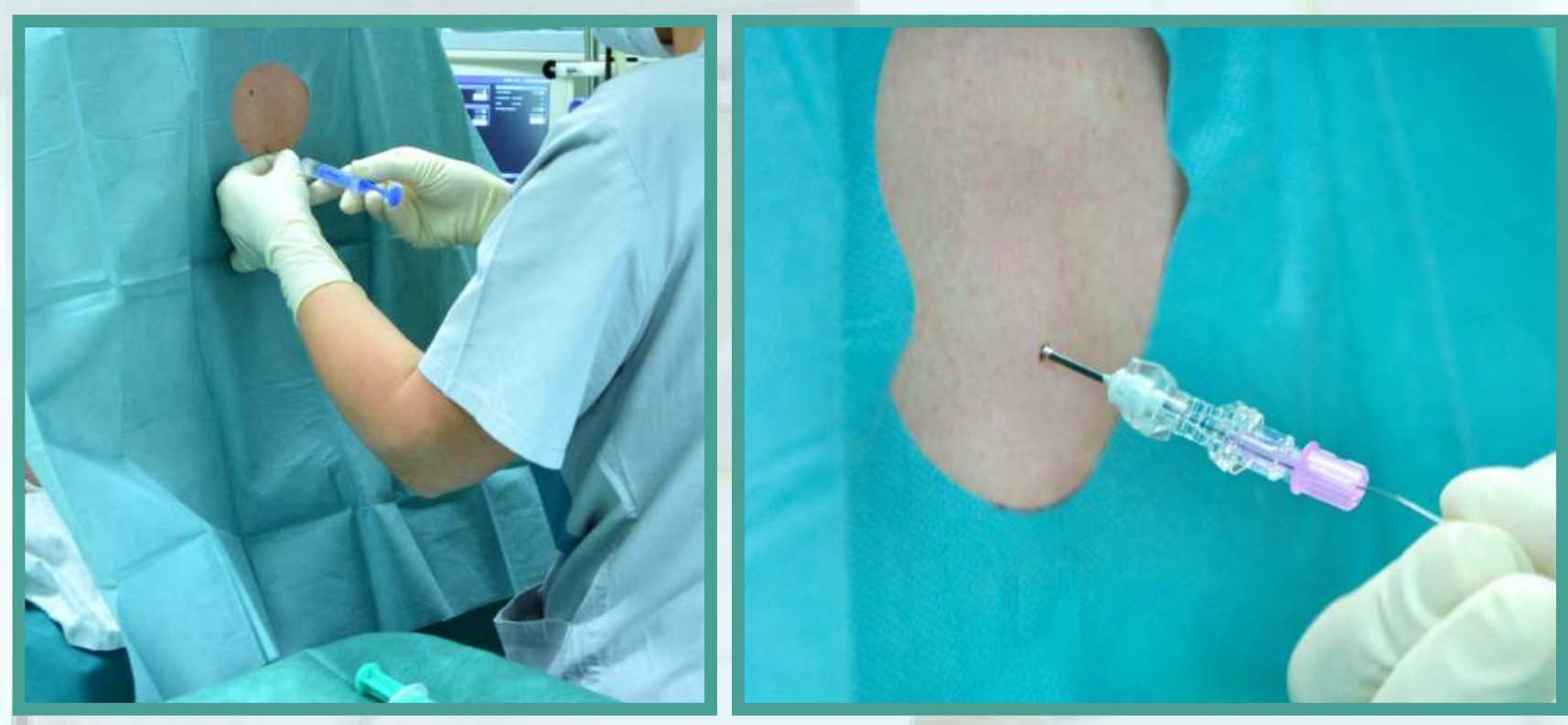

Conclusions: Regional anesthesia and surgical gastrostomy can be successfully performed in a frail geriatric patient when the underlying disease cause severe airway obstruction.

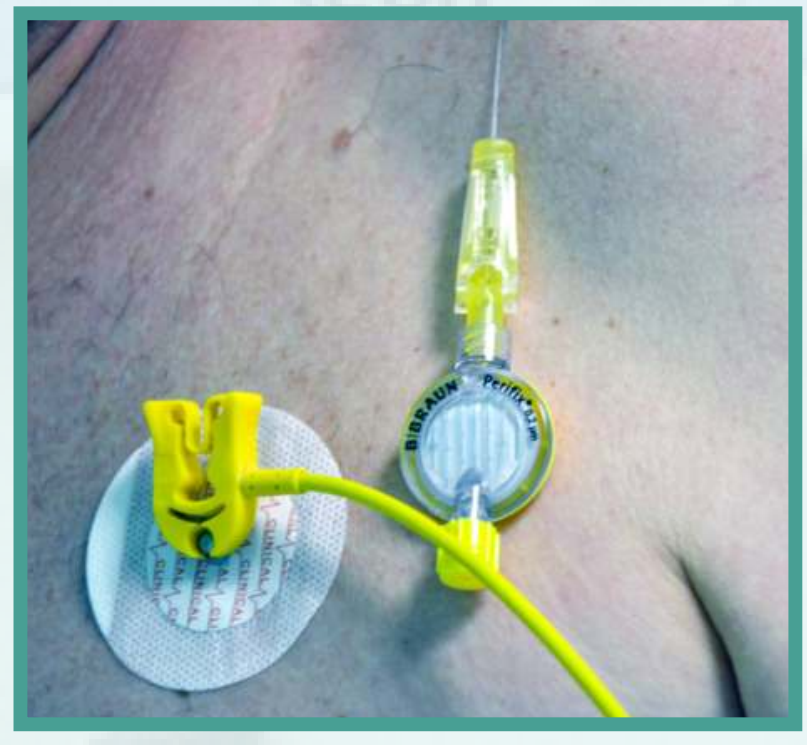

\section{References:}

1. Siegel R, Naishadham D, Jemal A. Cancer statistics, 2013. CA Cancer J Clin 2013;63(1):11-30.

2. Nugent B, Lewis S, O'Sullivan JM. Enteral feeding methods for nutritional management in patients with head and neck cancers being treated with radiotherapy and/or chemotherapy. Conchrane Database of Systematic Reviews 2013, Issue 1. Art No:CD007904.

3. Hunter KU, Jolly S. Clinical review of physical activity and functional considerations in head and neck cancer patients. Support Care Cancer 2013;21:1475-1479. 